\title{
TRASLADOS DE MIGRANTES FALLECIDOS DE ESTADOS UNIDOS A MICHOACÁN, MÉXICO
}

\author{
Transfers of deceased migrants from United States to Michoacan, \\ Mexico
}

\author{
Juan Carlos Ortíz Ruíz* \\ Sheyla Dafne Aguilar Magaña** \\ María Elena Rivera Heredia***
}

\begin{abstract}
Resumen. Esta investigación tiene por objetivo identificar las características sociodemográficas, causas de muerte, y distribución de las repatriaciones de restos realizadas desde los EUA al estado de Michoacán en México en los años 2005-2015, así como comprender el significado dado a la muerte y a la repatriación de los fallecidos por parte de sus familiares. Mediante un diseño mixto de investigación, se analizan los registros de michoacanos retornados con análisis descriptivos, y se retoma el testimonio de 3 familiares. Se identificó el retorno de 2950 cadaveres de migrantes fallecidos. En medio del dolor asociado con la muerte, el poder enterrar a su familiar, les ayuda a enfrentar la muerte como un hecho real que pueden constatar, mitigando con ello parte del sufrimiento de los dolientes.
\end{abstract}

Palabras clave: migración; muerte; repatriación; pérdida; significado.

\begin{abstract}
This research aims to identify the sociodemographic characteristics, causes of death, and distribution of the repatriations of remains made from the USA to the state of Michoacán in Mexico in the years 2005-2015, as well as to understand the meaning given to death and repatriation of the deceased by their relatives. Through a mixed methods research design, a descriptive analysis of the figures of returned people from Michoacan were analyzed, and the testimony of 3 relatives is included. The return of 2950 corpses of deceased migrants was identified. Amid the pain associated with death, being able to bury their family member helps them face death as a real event that they can verify, thereby mitigating part of the suffering of the mourners.
\end{abstract}

Keywords: migration; death; repatriation; loss; migration; meaning.

\footnotetext{
Facultad de Psicología de la Universidad Michoacana de San Nicolás de Hidalgo. Morelia, Michoacán, México. E-mail: la.paradoja@hotmail.com. Orcid: 0000-0003-0072-7835.

** Departamento de Derechos Humanos y Repatriación de la Secretaría del Migrante del Estado de Michoacán. Morelia, Michoacán, México. E-mail: petite.saguilar@gmail.com. Orcid: 00000003-4175-1436.

*** Universidad Michoacana de San Nicolás de Hidalgo. Morelia, Michoacán, México. E-mail: ceniem.umsnh@gmail.com. Orcid: 0000-0002-5835-0789.
} 


\section{Introducción}

En el año 2017 se estimó un total de 12.2 millones de mexicanos en los EUA, de los cuales el 51\% permanecen sin documentos. Para ese mismo año, 84.771 michoacanos contaron con matrícula consular, residiendo principalmente en los estados de California (45.6\%), Illinois (11.3\%) y Texas (11.2\%), y proviniendo principalmente de los municipios de Morelia (6.8\%), Apatzingán (4.3\%) e Hidalgo (4.2\%). En el rubro de las remesas, Michoacán fue la entidad con mayor monto recibido, redondeándose en 2,915 millones de dólares, siendo también el estado con mayor número de hogares beneficiados por las transferencias (199.481 hogares); las remesas se envían principalmente de forma mensual (43.6\%) y se usan en su mayoría para la compra de comida, vestido, gastos en salud o para pagar deudas (CONAPO, FUNDACIÓN BBVA BANCOMER y BBVA RESEARCH, 2018). Estas cifras resaltan la importancia que tienen las remesas para muchas familias michoacanas, llegando a ser una evidencia de la vinculación afectiva y de responsabilidad moral entre los migrantes y sus familiares que radican en su lugar de origen (Moctezuma, 2008).

La muerte ocurrida en el contexto del fenómeno migratorio México-EUA, reviste de importancia para la población michoacana, pues provienen de uno de los estados de la México con mayor tradición migratoria hacia los EUA (Pedraza, Navarro, Armas, 2007). El National Center for Health Statistics (NCHS, 2005 - 2015) del gobierno de los EUA, reporta que del año 2005 al año 2015 murieron un total de 929.293 personas de origen mexicano. Es posible asumir que los vínculos de carácter trasnacional existentes entre las familias que permanecen en Michoacán y los migrantes que viven en el exterior, no sólo se evidencian en el envío de remesas, sino también en los sucesos de muerte de éstos últimos. De acuerdo a Lestage (2008), la mayor parte de los migrantes mexicanos fallecidos en EUA son sepultados en aquél país; sin embargo, los restos de uno de cada 5 o 6 son enviados de vuelta a México para ser sepultados. La práctica de la repatriación de cadáveres es una constante, y da cuenta de la importancia de la filiación entre las familias mexicanas. Plantea que en seis años, de 2000 a 2006, un promedio anual de 8.000 cadáveres fueron enviados desde los Estados Unidos a México, y fueron trasladados desde los 50 estados que conforman la Unión Americana, principalmente desde los condados de Los Ángeles (California) con un promedio de 1.300 traslados de 2000 a 2006, seguido de Chicago (Illinois) con 650 en promedio para el mismo período, San Diego (California) con 488 y Dallas (Texas), con 478. Respecto a los lugares de destino de los traslados en la república mexicana, los estados identificados como expulsores de migrantes hacia Estados Unidos son los que contabilizan mayor número de repatriaciones de restos, destacando Michoacán, con un promedio de 388 traslados anuales. Alonso (2013) sugiere que el movimiento 
de restos humanos desde EUA a México puede tratarse de los más numerosos del mundo.

La práctica de las repatriaciones de restos implica la relación entre personas de espacios geográficos distintos, por una parte, los que se organizan en EUA para enviar el cuerpo del finado, y los que se organizan para recibirlo y sepultarlo (Calderón, 2014); sin embargo, es una temática escasamente abordada por la investigación en materia migratoria (Fernández, 2011), pero relevante para determinar las secuelas económicas, políticas, sociales y psicológicas que generan tanto en los lugares de origen como en los lugares de destino.

Este trabajo se avocó a explorar uno de los efectos psicológicos derivados de los eventos de fallecimiento de los migrantes, el cual es el duelo en los familiares que radican en Michoacán. El duelo es entendido como un proceso psicológico que lleva paulatinamente a las personas a asimilar y readaptarse a la pérdida de una persona significativa (Tizón, 2004). Es un proceso caracterizado por múltiples manifestaciones cognitivas, emocionales, conductuales y somáticas (como sensación de irrealidad, aturdimiento, incredulidad, alteraciones en el patrón de sueño, alteraciones alimenticias, negación, aislamiento, anhelo, añoranza, entre otras) y que conllevan una sensación de sufrimiento y aflicción en los dolientes. En este proceso, el doliente requiere ejecutar cuatro tareas principales para llegar a asimilar la pérdida de un familiar, que son aceptar la realidad de la pérdida, reconocer las emociones y el dolor de la pérdida, adaptarse a un entorno en el que la persona significativa se encuentra ausente, y recolocar emocionalmente al fallecido. No hay un consenso respecto al tiempo de duración de un duelo normal, pudiendo abarcar desde 6 meses hasta años, pero se considera como duelo patológico o complicado los casos en los que los dolientes manifiestan malestar que les resulta incapacitante (Worden, 2013).

En el campo de la migración internacional, Achótegui (2004) plantea que el hecho de migrar implica pérdidas significativas para los migrantes, que son principalmente la pérdida de la familia y los seres queridos, la pérdida de la lengua, la cultura, la tierra, el estatus social, el grupo de pertenencia, y la seguridad. Falicov (2002) resalta que tanto el migrante como sus familiares que se quedan en su lugar de origen experimentan la llamada pérdida ambigua, que en este contexto se manifiesta en el deseo o la esperanza del regreso al lugar de origen, o de reencontrarse con los familiares. Ya que la ausencia del migrante o de los familiares, aunque sea prolongada, no representa una pérdida definitiva, la esperanza del reencuentro da lugar a sentimientos ambivalentes, debido a lo incierto que puede resultar volverse a ver, sobre todo en casos de migración indocumentada. Por ello, los seres queridos están psicológicamente presentes en el recuerdo, pero físicamente ausentes. Estas son las características distintivas de la pérdida ambigua: la incertidumbre y la 
ambivalencia afectiva, donde la persona únicamente adquiere certeza cuando la pérdida se vuelve innegable y definitiva, como en los casos de muerte (Boss, Yeats, 2014).

Con la intención de ampliar el conocimiento sobre el traslado de migrantes que fallecieron en Estados Unidos a su lugar de origen en el estado de Michoacán, México, así como el significado de dicha experiencia en los familiares que se quedaron en espera y recibieron los restos del migrante, el presente trabajo parte de dos objetivos de investigación, primero, identificar el número de repatriaciones de occisos realizadas a Michoacán desde los Estados Unidos durante el periodo de 2005 a 2015; y el segundo, analizar las experiencias de los dolientes radicados en Michoacán en torno a la muerte y la repatriación del cuerpo de sus familiares migrantes, e identificar algunas de las implicaciones psicológicas que éstas tienen en sus procesos de duelo.

\section{Método}

Se utilizó una metodología mixta, de alcance exploratorio. En la fase cuantitativa se realizó un análisis de frecuencias para identificar el número de repatriaciones de occisos realizadas a Michoacán en el periodo 2005-2015, identificando la edad y sexo de los fallecidos, las causas de muerte, los lugares de los Estados Unidos desde las que fueron enviados los cuerpos, y los municipios de Michoacán a los que estos arribaron, con base en los registros de los traslados de occisos realizados por la Secretaría del Migrante del Estado de Michoacán (SEMIGRANTE).

En la fase cualitativa, se realizaron entrevistas a profundidad a tres participantes, que gestionaron ante la Secretaría del Migrante la repatriación del cuerpo de su familiar fallecido. Los criterios para recabar los testimonios fueron que los participantes fuesen mayores de edad, familiares directos de los occisos, y que hubiesen gestionado el traslado del cuerpo ante la Secretaría del Migrante. Se les localizó con apoyo de la Dependencia, y con los que aceptaron participar en la investigación, se acordó una cita para realizar las entrevistas a profundidad. Las entrevistas se realizaron en los municipios donde radican los participantes, se registraron sus testimonios con grabaciones de audio, y posteriormente fueron transcritas y analizadas desde una perspectiva fenomenológica, identificándose los siguientes ejes temáticos: 1) los sucesos de muerte; 2 ) incertidumbres y dudas en torno a la muerte de los migrantes; 3 ) la toma de decisión sobre la repatriación del cuerpo; y 4) las manifestaciones del duelo en los familiares del migrante fallecido. 
Tabla 1 - Características de los occisos y de los familiares que compartieron su testimonio

\begin{tabular}{c|c|c|c|c|c|c}
\hline $\begin{array}{c}\text { Sexo y edad } \\
\text { del occiso }\end{array}$ & $\begin{array}{c}\text { Lugar de EUA } \\
\text { donde murió }\end{array}$ & $\begin{array}{c}\text { Año en que } \\
\text { murió }\end{array}$ & $\begin{array}{c}\text { Causa de la } \\
\text { muerte }\end{array}$ & $\begin{array}{c}\text { Municipio de } \\
\text { origen y al } \\
\text { que regresó }\end{array}$ & $\begin{array}{c}\text { Nombre del } \\
\text { familiar }\end{array}$ & $\begin{array}{c}\text { Parentesco y } \\
\text { edad }\end{array}$ \\
\hline $\begin{array}{c}\text { Hombre de } \\
36 \text { años }\end{array}$ & Arizona & 2013 & Asfixia & Irimbo & Rosalba* & $\begin{array}{c}\text { Hermana de } \\
34 \text { años }\end{array}$ \\
$\begin{array}{c}\text { Hombre de } \\
24 \text { años }\end{array}$ & California & 2013 & Accidente & Acuitzio & Rolando* & $\begin{array}{c}\text { Hermano de } \\
28 \text { años }\end{array}$ \\
$\begin{array}{c}\text { Hombre de } \\
32 \text { años }\end{array}$ & California & 2014 & Suicidio & Uruapan & Mónica* & $\begin{array}{c}\text { Madre de } 53 \\
\text { años }\end{array}$ \\
\hline
\end{tabular}

* Para preservar la confidencialidad de los participantes se modificaron sus nombres originales. Elaboración propia.

\section{¿Por qué murieron, de dónde vinieron y a dónde arribaron los difuntos michoacanos?}

Los registros de repatriaciones de restos de migrantes michoacanos, ya fuese como residentes o al intentar cruzar la zona fronteriza, comenzaron a capturarse en el 2005, año donde se registraron 204 casos (6.9\%). Con respecto a esta cifra inicial, resalta una tendencia de incremento en 2006 en el que se registraron 331 casos (11.2\%), más del 50\% respecto al registro anterior. A partir de este año y hasta 2010 se tienen más de 300 casos por año siendo 2009 el que más repatriaciones registró con 334 casos (11.3\%), seguidos de 2006 con 331 y 2010 con 327 (11\%). En contraste, partiendo de 2011, se marcó una tendencia a la baja que culminó en el año 2015 con 176 casos (Figura 1).

Figura 1 - Distribución de casos de repatriaciones de migrantes michoacanos fallecidos ocurridas por año en el periodo 2005-2015

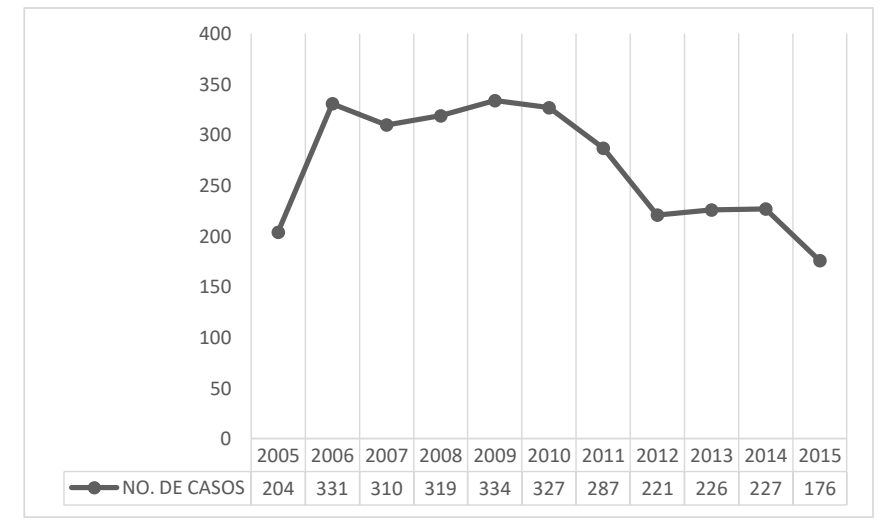

Fuente: Elaboración propia a partir de los datos proporcionados por la SEMIGRANTE. 
Hasta mediados del año 2011 la SEMIGRANTE comenzó a registrar la edad y el sexo de los fallecidos; sólo en 955 casos se encuentran especificados dichos datos. La mayor cantidad de fallecidos repatriados a Michoacán se concentra en el grupo de edad de los 45 a los 54 años de edad (162 casos), seguidos del grupo de 35 a 44 años (154 casos) y del grupo de 55 a 64 años (152 casos). Respecto al sexo, 732 fallecidos son de sexo masculino (76.6\%) y $223(23.4 \%)$ de sexo femenino, lo cual puede marcar la tendencia de los datos faltantes. Las causas principales de muerte son los accidentes, con 591 casos (20\%); la segunda son las enfermedades del corazón, seguida del cáncer $(12.4 \%)$, el 9.9\% de los casos permanece con causas de muerte desconocidas, y los homicidios representan el $8.2 \%$ (Tabla 2). En estos cinco apartados se concentra el $65.3 \%$ de los casos totales.

Tabla 2 - Causas de muerte más frecuentes entre los fallecidos repatriados a Michoacán

\begin{tabular}{|c|c|c|c|}
\hline $\mathbf{N}$ & Causa de muerte & $\begin{array}{c}\text { Números de } \\
\text { casos }\end{array}$ & $\%$ \\
\hline 1 & Accidentes & 591 & 20 \\
\hline 2 & Enfermedades del Corazón & 443 & 15 \\
\hline 3 & Cáncer & 366 & 12.4 \\
\hline 4 & Desconocidas & 292 & 9.9 \\
\hline 5 & Homicidio & 243 & 8.2 \\
\hline 6 & Enfermedad cerebrovascular & 151 & 5.1 \\
\hline 7 & Muerte natural & 136 & 4.6 \\
\hline 8 & Problemas Respiratorios & 90 & 3 \\
\hline 9 & Suicidio & 81 & 2.7 \\
\hline 10 & Diabetes & 76 & 2.6 \\
\hline 11 & Exposición a los medios & 68 & 2.3 \\
\hline 12 & Enfermedades en el hígado & 67 & 2.3 \\
\hline 13 & Ahogamiento & 56 & 1.9 \\
\hline 14 & Otro Tipo de Muerte Violenta & 52 & 1.8 \\
\hline 15 & Problemas Renales & 45 & 1.5 \\
\hline 16 & Paro Cardiaco y/o Respiratorio & 30 & 1 \\
\hline 17 & Alcoholismo y drogadicción & 30 & 1 \\
\hline 18 & Tipos de Infecciones & 28 & 0.9 \\
\hline 19 & Lesiones y/o traumatismos & 21 & 0.7 \\
\hline 20 & Fallas Multiorgánicas & 18 & 0.6 \\
\hline
\end{tabular}

Fuente: elaboración propia a partir de los datos proporcionados por la SEMIGRANTE. 
Respecto a los traslados de occisos por estado de EUA, los 2.962 casos de repatriaciones se distribuyen de manera muy distinta. En California se concentra el mayor número de traslados con 1.466 casos (49.5\%), le sigue Illinois con 223 casos (7.5\%) y Arizona con 126 (4.3\%). En cuanto al destino de los occisos, arribaron a los 113 municipios de Michoacán, mayormente a los más poblados: Morelia con 326 casos (11\%), Uruapan con 95 (3.2\%) y Lázaro Cárdenas con 80 (2.7\%) (Tabla 3).

Tabla 3 - Diez principales lugares de partida de los Estados Unidos y municipios de destino de los traslados de los migrantes fallecidos en el estado de Michoacán, México

\begin{tabular}{c|l|c|l|c}
\hline Origen & $\begin{array}{c}\text { Número de } \\
\text { traslados }\end{array}$ & \multicolumn{1}{|c}{ Destino } & $\begin{array}{c}\text { Número de } \\
\text { Traslados }\end{array}$ \\
\hline 1 & California & 1.466 & Morelia & 326 \\
2 & Illinois & 223 & Uruapan & 95 \\
3 & Arizona & 126 & Lázaro Cárdenas & 80 \\
4 & North Carolina & 114 & Zitácuaro & 69 \\
5 & Texas & 113 & Tarímbaro & 68 \\
6 & Georgia & 90 & Tacámbaro & 67 \\
7 & Florida & 84 & Zinapécuaro & 67 \\
8 & Washington & 84 & Maravatío & 63 \\
9 & Oregon & 71 & Hidalgo & 61 \\
10 & Nevada & 62 & Apatzingán & 58 \\
\hline
\end{tabular}

Fuente: Elaboración propia en base a los datos de la SEMIGRANTE.

Si bien en términos numéricos los municipios más poblados son los que realizan mayor cantidad de traslados, al comparar el número de repatriaciones con el número de habitantes por municipio, se obtuvo una tasa que representa el porcentaje de cada municipio. Así es como se encontró que hay municipios que proporcionalmente a su número de habitantes han realizado más traslados de restos que las zonas más pobladas de la entidad (Tabla 4).

Vista Hermosa, Chavinda y Epitacio Huerta, municipios con grado Alto y Muy Alto de intensidad migratoria son los más bajos en cuanto a tasa de repatriación. Mientras que Zamora, Uruapan, Jacona, Tlalpujahua, Peribán y Ziracuaretiro se encuentran en grado Medio con bajas tasas de traslados de cuerpos (ver Tabla 5). 
Tabla 4 - Los diez municipios de Michoacán, México con tasas más altas de repatriaciones de restos

\begin{tabular}{c|l|l|c|c|c}
\hline Posición & Municipio & $\begin{array}{l}\text { No. de } \\
\text { habitantes }\end{array}$ & $\begin{array}{l}\text { No. de } \\
\text { Repatriaciones } \\
\text { de restos }\end{array}$ & $\begin{array}{l}\text { Tasa de } \\
\text { Repatriaciones } \\
\text { de Restos }\end{array}$ & G.I.M*. \\
\hline 1 & Chucándiro & 4559 & 20 & 0.438 & Muy Alto \\
2 & Churintzio & 5016 & 13 & 0.259 & Alto \\
3 & Coeneo & 20749 & 53 & 0.255 & Muy Alto \\
4 & Huaniqueo & 8093 & 19 & 0.235 & Muy Alto \\
5 & Carácuaro & 9485 & 20 & 0.210 & Alto \\
6 & Cherán & 19081 & 40 & 0.209 & Alto \\
7 & Copándaro & 9151 & 19 & 0.207 & Muy Alto \\
8 & Villamar & 17166 & 35 & 0.203 & Muy Alto \\
9 & Angamacutiro & 15193 & 30 & 0.197 & Alto \\
10 & Lagunillas & 5571 & 11 & 0.197 & Muy Alto \\
\hline
\end{tabular}

* Grado de Intensidad Migratoria. Es una medida que resume las características migratorias de los hogares mexicanos en términos de remesas, migrantes residentes en Estados Unidos, migrantes circulares y migrantes de retorno.

Fuente: Elaboración propia a partir de los datos de CONAPO (2010) y los proporcionados por la SEMIGRANTE.

Tabla 5 - Municipios con baja tasa de repatriaciones de restos de Michoacán, Mexico

\begin{tabular}{l|l|c|c|l|l}
\hline Posición & Municipio & $\begin{array}{l}\text { No. de } \\
\text { habitantes }\end{array}$ & $\begin{array}{l}\text { No. de } \\
\text { Repatriaciones } \\
\text { de restos }\end{array}$ & $\begin{array}{l}\text { Tasa de } \\
\text { Repatriaciones } \\
\text { de Restos }\end{array}$ & G.I.M. \\
\hline 104 & Zamora & 196208 & 56 & 0.0285 & Medio \\
105 & Uruapan & 334749 & 95 & 0.0284 & Medio \\
106 & Jacona & 69744 & 17 & 0.0244 & Medio \\
107 & Vista Hermosa & 20624 & 5 & 0.0242 & Alto \\
108 & Tingambato & 15010 & 3 & 0.0200 & Bajo \\
109 & Tlalpujahua & 27788 & 4 & 0.0144 & Medio \\
110 & Peribán & 27832 & 4 & 0.0144 & Medio \\
111 & Ziracuaretiro & 17394 & 2 & 0.0115 & Medio \\
112 & Chavinda & 10258 & 1 & 0.0097 & Muy Alto \\
113 & Epitacio Huerta & 16622 & 1 & 0.0060 & Alto \\
\hline
\end{tabular}

Fuente: Elaboración propia a partir de los datos de CONAPO (2010) y los proporcionados por la SEMIGRANTE. 
Figura 2 - Municipios de Michoacán con altas y

bajas tasas de traslados de occisos

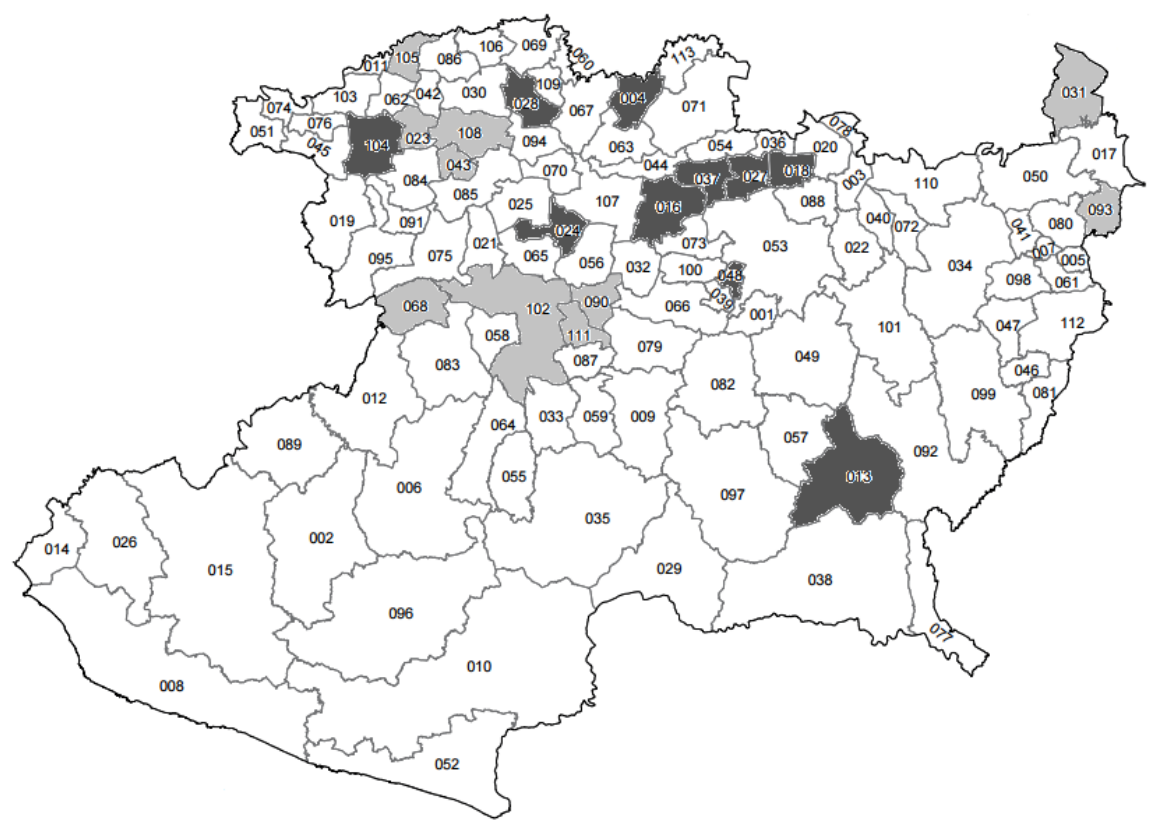

\begin{tabular}{l|l|l|l}
\hline \multicolumn{2}{c|}{$\begin{array}{c}\text { Municipios con alta tasa de } \\
\text { repatriaciones de restos }\end{array}$} & \multicolumn{2}{c}{$\begin{array}{c}\text { Municipios con baja tasa de } \\
\text { repatriaciones de restos }\end{array}$} \\
\hline 027 Chucándiro & 024 Cherán & 108 Zamora & 093 Tlalpujahua \\
\hline 028 Churintzio & 018 Copándaro & 102 Uruapan & 068 Peribán \\
\hline 016 Coeneo & 104 Villamar & 043 Jacona & 111 Ziracuaretiro \\
\hline 037 Huaniqueo & 004 Angamacutiro & 105 Vista Hermosa & 023 Chavinda \\
\hline 013 Carácuaro & 048 Lagunillas & 090 Tingambato & 031 Epitacio Huerta \\
\hline
\end{tabular}

Fuente: Elaboración Propia con base en los datos de la SEMIGRANTE.

La mayor cantidad de municipios con elevadas tasas de repatriaciones de restos y con mayor número de traslados de éstos se concentran en la región Cuitzeo, mientras que los municipios con bajas tasas de repatriaciones se concentran en la región Lerma-Chapala y en la región Purépecha (Figura 2).

\section{Las experiencias de los dolientes}

En función de los tres testimonios analizados, fue posible detectar elementos en común. Primeramente, los migrantes fallecidos partieron a los 
EUA con el objetivo de mejorar las condiciones económicas de vida, tanto las propias como de sus familias, eran jóvenes al momento en que se fueron; sus edades oscilaban entre los 16 y los 18 años; cruzaron la frontera norte de manera indocumentada y realizaron trabajos que pueden ser considerados de baja cualificación, lo cual encaja con el perfil general de los migrantes mexicanos en EUA, ampliamente identificado (CONAPO, 2010). Decidieron emprender el viaje a los EUA a partir de la referencia de los familiares próximos, entendiendo el migrar como una forma de conseguir sus sueños, o de superación personal.

Sus testimonios coinciden en dos aspectos referentes a las expectativas de los actores: mientras los migrantes pretendían permanecer en EUA, ya fuese para radicar permanentemente, regularizar su estatus migratorio, para enviar dinero, o bien por motivos poco claros, la expectativa de sus familiares era una constante: que regresaran su lugar de origen.

\section{Los sucesos de muerte}

Los testimonios aluden tres escenarios distintos de muerte. El primero ocurrido al intentar cruzar la frontera norte con EUA, en la zona desértica de Arizona, el migrante murió debido a que el coyote abandonó la camioneta que transportaba migrantes indocumentados, dejándolos encerrados a él, su esposa y a otras personas que viajaban con ellos por horas en condición de hacinamiento y vulnerables a las altas temperaturas del desierto hasta que fueron rescatados. El segundo testimonio hace referencia a un accidente automovilístico en una carretera del estado de California, ocurrido cuando el ahora occiso conducía de vuelta a su hogar después de cumplir su jornada laboral en la fábrica en la que trabajaba, en vísperas del 14 de febrero. La viuda dio aviso a la madre del difunto, mencionando que él chocó contra un árbol. El tercer testimonio hace referencia a un suicidio. Los primos del difunto le comentaban a su madre que lo habían baleado en una ocasión, quedando gravemente herido, y que a pesar de que fue mostrando mejoría, consumía alcohol en exceso y dejó de asistir a sus revisiones médicas. Una vez que encontraron el cuerpo del difunto, sus primos no querían dar aviso a su madre con la intención de aminorar su sufrimiento, debido a que su hija hacía tres años entonces, se había suicidado en su domicilio. Sin embargo, ella reporta que presentía la muerte de su hijo.

Sobre el suceso de muerte

Esa noche recibí una llamada de mi hermano el más chico: "Habló Alondra desde antier, que los dejaron en la camioneta. Roque se ahogó, pero todavía llegó al hospital, y dice que devolvió, mucha sangre por la nariz, por los oídos y por los ojos". Después mi hermana nos dijo que le habían dicho que se le habían cocido todos sus órganos por el calor, como quedaron... no sé si se descompondría la camioneta, o los abandonaron, no sé, porque duraron muchas horas abandonados en el desierto. Siquiera les hubieran abierto la puerta. (Rosalba, participante 1. Irimbo, 2016) 
Él se iba a trabajar toda la semana, allá se quedaba en el trabajo, y se iba a su casa cada fin de semana. Trabajaba lejos de donde vivía. Para amanecer el 14 de febrero, porque según iban a pasar juntos el día 14, fue cuando se accidentó. La noticia de que había muerto se la dieron a mi mamá. Le hablo la señora, la mamá de sus niños. Dijo que había tenido un accidente y que había fallecido. Lo único que le comentó fue que él iba del trabajo a su casa y que chocó contra un árbol. (Rolando, participante 2. Acuitzio, 2016)

Según los sobrinos de mi esposo no querían echármelo para acá. Que decían: "no hay que darle ese disgusto a mi tía. Apenas se está recuperando de su hija. No hay que darle ese disgusto, se va a morir esta vez, vamos a decir que él vive". Y no me querían decir. Pero uno de madre lo soñaba, que mi hijo estaba muerto, y que él venía y que estaba tirado aquí. Y yo les hablaba: ¿Qué pasa? ¿Algo pasó verdad? ¿Por qué no me quieren decir? Yo decía "¿por qué que se me viene esta tristeza? algo pasó". Hasta que me dijeron: "si tía, nos culpamos mucho porque nosotros lo animamos a venir y no lo supimos cuidar, se quitó la vida". (Mónica, participante 3. Uruapan, 2016)

\section{Incertidumbre ante el suceso de muerte}

A pesar de que se trata de eventos de muerte repentina (Muerte por asfixia, Accidente automovilístico, y suicidio), y es de esperar que los familiares reaccionen con negación e incredulidad (Worden, 2013), la experiencia de los dolientes retrata una particularidad. Los familiares de los migrantes fallecidos, al ser notificados de la muerte, trataron de reconstruir el suceso de muerte a través de los testimonios de las autoridades, y de los familiares, amigos o allegados que radicaban con el difunto en los Estados Unidos. La resultante es que se toparon con diferentes versiones del suceso, aumentando su sensación de incertidumbre y confusión al momento de tratar de explicarse lo sucedido. Esto remite a la pérdida ambigua, tipo de pérdida por la que atraviesan los migrantes y sus familiares al dejar su lugar de origen (Boos, Yeats, 2014; Achotegui, 2009; Falicov, 2002), y que se presenta también en los sucesos de muerte. Éste tipo de pérdida se manifiesta en la dificultad para reconstruir el suceso de muerte en un relato coherente que pueda esclarecer para los dolientes tanto las circunstancias de la muerte, como las situaciones que inquietaban al migrante en vida. La incertidumbre ante el suceso de muerte, ligado a la imposibilidad de los familiares de estar próximos al fallecido en espacio y tiempo, constituye una dificultad para la asimilación del suceso (Ortíz, Rivera, 2018).

Versiones de la muerte

Ya no supimos a dónde acudir para saber más. Son muchas las cosas que... unos dicen una cosa, luego otros dicen otras. Se contradicen. Hay un señor que estaba allá que dice que salieron en las noticias la camioneta y las credenciales. Y mi hermana dice que duró mucho tiempo en las redes el video, pero nada más se le ven sus tenis, y a mi cuñada nada más se le ve la espalda. (Rosalba, participante 1. Irimbo, 2016)

Ya cuando vimos el reporte de cómo había sido, decía que había chocado contra un árbol. Lo digo porque primero decían que chocó contra una barda, y que había 
chocado contra un depósito de los del agua, o que otra camioneta lo golpeó para sacarlo del camino, que ya lo estaban cuidando afuera de una tienda. Muchas, muchas versiones pues. (Rolando, participante 2. Acuitzio, 2016)

Sus primos me dijeron: "Andaba crudo y borracho, y se la pasaba tomando porque le dolía mucho lo que le había pasado a su hermana y que él no estaba. A él lo habían golpeado y no podía trabajar muy bien ya". Sus primos le dijeron "ipor qué no le mandas dinero a tu mamá, si se la está pasando difícil por los tres niños que le dejaron? Tú ganas y ganas y a puro tomar". Tal vez a éste le agarró la depresión y ha de haber dicho "para nada sirvo", por eso se quitó la vida. (Mónica, participante 3. Uruapan, 2016)

\section{Dudas sobre la muerte}

Yo quisiera saber de qué forma murió, o cómo. Me gustaría saber si cuando lo sacaron de ahí ya estaba muerto, o si murió en el hospital. (Rosalba, participante 1. Irimbo, 2016)

Uno se siente de manos atadas porque realmente uno no puede saber, ciertamente, como si el accidente hubiera sido aquí en México; aquí tú vas e investigas, o con simplemente ir al lugar del accidente ahí te das cuenta. No ocupas ser perito para darte cuenta de cómo sucedieron más o menos las cosas. Pero así no puede hacer uno nada, no puedes darte cuenta, ni cómo paso, ni de dónde paso, ni nada. Lo único que tenemos, o pedimos, fue el acta de defunción, donde dice de qué murió; pero no se puede que vaya a ver cómo fue o por qué fue, o preguntar, no, nadie te dice eso. (Rolando, participante 2. Acuitzio, 2016)

Yo no creo que él se haya matado, porque cuando lo balacearon él tenía mucho miedo a morir (...) yo siento que lo mataron los cholos con los que andaba, y pues para saber quiénes son. Dicen que eran desconocidos, que con él eran amigos. Y por lo menos yo digo, si yo llego a California, si Dios me ayuda a que salga bien mi visa y que yo llegue ahí, de menos voy a ver su ropa, o en qué lugar estaba. Mi sueño es ir nomás, saber dónde murió. (Mónica, participante 3. Uruapan, 2016)

\section{La Repatriación del cuerpo}

En los relatos se identificaron tres aspectos relevantes implicados en el traslado de los cuerpos de los fallecidos. El primero de ellos consiste en que la decisión de la repatriación de los restos, en los tres casos, se priorizó el deseo de las madres de los difuntos, aún en los casos en los que los fallecidos habían formado familia en los EUA.

\section{Decisión de la repatriación del cuerpo}

Nos habló mi hermana, porque su esposa lo quería enterrar allá. Y dijo mi mamá que no, y mi cuñada dijo que si lo queríamos traer, pues lo trajéramos. (Rosalba, participante 1. Irimbo, 2016)

Traer el cuerpo de mi hermano lo decidió mi mamá más que nada. (Rolando, participante 2. Acuitzio, 2016)

"Vamos a mandárselo a mi tía". A mi nomás me dijeron, ya te lo mandamos para allá, los primos que viven allá. "Ya se va para allá". (Mónica, participante 3. Uruapan, 2016)

La gestión del traslado del cuerpo es descrito como un proceso tortuoso, en el cual los familiares, desde el momento en que recibieron la notificación del deceso, hasta que el cuerpo fue repatriado a Michoacán, reportan 
haberlo vivido con incertidumbre y angustia, debido a que no sabían si el traslado del cuerpo se llevaría a cabo; reconocen que esto es originado por el desconocimiento de los trámites burocráticos necesarios para efectuar el traslado, trámites que hacen que el proceso demore de 10 hasta 30 días dependiendo del caso. Relatan que en los días que comprenden el periodo, los sentimientos de dolor y sufrimiento quedan suspendidos, fantaseando que posiblemente la notificación de la muerte fue errónea, teniendo la esperanza de que se trate de un error; incertidumbre que concluye hasta que el cuerpo arriba finalmente. A la llegada del cuerpo del difunto, los familiares manifiestan que el dolor y el sufrimiento que sintieron al momento de ser notificados de la muerte del migrante, resurge con intensidad al momento de arribar éste a la localidad de origen.

La visión del cuerpo del difunto derivado del proceso de repatriación, en los testimonios figura primordialmente como la prueba indiscutible de la realidad del fallecimiento del migrante, y constituye el principal motivo para que la repatriación del cuerpo se efectúe (Ortíz, Rivera, 2018). Esta práctica resulta fundamental para aliviar parcialmente la incertidumbre generada ante la notificación del suceso de muerte. El hecho de que la repatriación del cuerpo demore semanas en efectuarse, implica que la primer tarea del duelo, que es el de aceptar la realidad de la pérdida (Worden, 2013), quede pospuesta y suspendida hasta que el cuerpo finalmente arriba. Sin embargo, la repatriación del cuerpo reviste también otro sentido, que es el de una forma de retorno, retorno al lugar de origen, retorno a los familiares, retorno que significa una tragedia y en el caso de la participante 3, retorno que significa también un fracaso.

La repatriación del cuerpo como prueba de realidad y como una forma de regreso

Mejor enterrarlo aquí. Sí porque, sufriríamos más yo creo, si no lo hubiéramos visto, que si no viéramos dónde quedó enterrado. Mis hermanos decían que nos asomáramos bien para ver si era, pues él. El día que lo trajeron, venía bien rasurado, bien frío, porque yo lo toqué, en toda su caja, bien, bien congelado. Y el día que lo íbamos a enterrar ya tenía su barba crecida. Y así como era de chico, ya empezaba a tener canas. Sufrimos muchísimo, porque estaba que ya lo mandaban o no lo mandaban. Pero hubiera sido peor que lo hubieran dejado allá, y ni saber dónde había quedado ni cuándo... no nos costó nada. Todo lo apoyó, me imagino las oficinas del migrante. (Rosalba, participante 1. Irimbo, 2016)

Mi mamá quería sentirse de alguna forma más... más conforme de ver el cuerpo... aunque fuera el cuerpo de su hijo. Porque ella decía, y si, igual y nosotros también así nos sentimos, si lo hubieran sepultado allá... no lo puedes asimilar, de tal manera como si tú ves el cuerpo y lo sepultas. Siento que si hubiera quedado por allá, te estuvieras preguntando si sería cierto, no sería cierto, si sería él o no sería él... o cómo estaría, o, mil cosas. Entonces ese fue el querer traer su cuerpo a México. En verlo físicamente. Y pues así ya sabes que está muerto y listo. Pero tú sabes dónde... tú lo viste físicamente, que realmente si era él. Y si se hubiera 
quedado allá te digo, hubieran sido mil preguntas... sin respuesta. Eso hubiera pasado. Y por siempre... (Rolando, participante 2. Acuitzio, 2016)

Yo le decía: "vente hijo tú eres el único apoyo que nos vas a apoyar, porque tú no estás casado". "Si mamá, este año ya me voy a venir, espérate, este año me vengo" me dijo él. Y nunca se venía, ya hasta que se vino muerto... Aunque yo sé que el cuerpo lo sepulté aquí, pero para saber qué le diría a sus amigos, o qué pena traía o qué sentiría él. Cuando me lo mandaron muerto pues ya lo sepulté también. A mi hija la sepulté aquí en el panteón de San Pedro, y a aquél lo sepulté en el panteón del hospital porque ya no había espacio. Separados nos quedamos ya nosotros. Pero de ahí fracasamos bien harto. (Mónica, participante 3. Uruapan, 2016)

\section{Las manifestaciones del duelo}

Los participantes expresan que tanto ellos como sus familiares cercanos presentaron una serie de manifestaciones asociadas al duelo a partir del suceso de muerte del migrante, como atesoramiento de los objetos del difunto, llanto recurrente, problemas de presión arterial, tabaquismo, alcoholismo, desgaste físico, ansiedad, alteraciones del sueño, alteraciones en los hábitos alimenticios, tristeza y deseos de morir; síntomas que se enmarcaron, en el caso de los participantes 1 y 2 , en las afectaciones económicas de la muerte puesto que recibían remesas de manera frecuente, y en la desvinculación entre la esposa y los hijos de los difuntos radicados en Estados Unidos y los familiares del difunto que radican en Michoacán; y en el caso de la participante 3, los síntomas se enmarcaron en el proceso de duelo previo por el suicidio de su hija, y en un allanamiento violento a su domicilio en el que la agredieron físicamente y le robaron sus pertenencias.

Mis papás dicen que están bien, pero luego mi mamá ve las cosas de él, su ropa, y se pone mal, siempre se le sube la presión mucho. Apenas en esta semana, dijo que iba a regalar su ropa, o la iba a quemar, y la empezó a sacar y le subió muchísimo la presión, y de vuelta la volvió a guardar. Y yo creo nunca la va ni a dar ni a quemar. Ahí tiene todas sus cosas en su casa. Ya le dicen que las deje o que otra gente les de uso. Y no quiere. Ni ella les da un uso ni... se está aferrando mucho a él. Mi papá de por si era muy grande. Se acabó, se acabó mi papá. Mi mamá también, que es grande pero, mi papá es mayor que ella como 16 años, mi mamá no tenía canas y ahorita está cubierta de canas. Mi mamá es hipertensa, y se le sube mucho la presión. Y a mí desde entonces se me sube a veces. Papá siempre termina fumando. Ya fumaba desde antes, pero no igual. Y yo estoy bien. Solo cuando, pues me quedo sola y... y empiezo pues a recordar así, me dan ganas de llorar. Hago lo posible por no estar aquí sola también. No me gusta estar sola. Se pone uno a recordar cosas que, ya no tiene caso, ni modo, ya pasó, ya... no me gusta estar sola porque para donde quiera que... que vea uno, se acuerda de muchísimas cosas. (Rosalba, participante 1. Irimbo, 2016)

Es difícil asimilarlo, él era mi único hermano y pues sí, sentimentalmente fue donde me afectó mucho a mí, como hermano; pero a mi mamá y mis hermanas fue de todo tipo, económicamente pues, él era el que les aportaba. Y si cambia mucho la vida de una persona así. Mi mamá duró mucho tiempo deprimida e inquieta; en los primeros días no comía nada, ya después empezó a comer un poco. Igual, no podía dormir bien. Y dicen que no estaba a gusto ni en su casa ni en otro lado. 
A ella fue a la que más le pegó la depresión. Si. Y te estoy hablando como unos 6 meses así de mal. (Rolando, participante 2. Acuitzio, 2016)

Yo por mí, le digo, yo a la muerte no le tengo miedo, yo inclusive le pedí mucho a Dios que me recogiera, que quería estar junto con mi hija, no quería estar viva, y no tener a mi hija aquí. Cuando trajeron a mi hijo, y que lo sepultamos, a los dos meses es cuando me llegan a golpearme y a robarme todo. (Mónica, participante 3. Uruapan, 2016)

\section{Reflexiones}

La práctica de las repatriaciones de occisos puede considerarse como una modalidad de la migración de retorno, al implicar el regreso del migrante sin vida. En Michoacán, estado de larga tradición migratoria hacia los Estados Unidos, resulta una práctica constante, que se ve reflejada en los registros de las gestiones de la Secretaría del Migrante. Es necesario acotar que no son cifras concluyentes dado que no reflejan la totalidad de los traslados de occisos realizados a Michoacán. Para ejemplificar, en una publicación reciente del número de traslados de occisos de la Secretaría de Relaciones Exteriores, se promedian 500 traslados por año del 2010 al 2018 (SRE, 2018), mientras que las cifras de la SEMIGRANTE varían, promediando 244 traslados anuales de 2010 a 2015. Esto implica, que no todos los traslados a Michoacán realizados en ese periodo se llevan a cabo a través de la mediación de la SEMIGRANTE, sino que los usuarios pueden hacer uso solamente del subsidio federal, o recurrir al apoyo de asociaciones, familiares y paisanos para realizar los traslados, y esos casos, la dependencia los desconoce.

Las causas de muerte revelan que los michoacanos mueren más por enfermedades relacionadas con padecimientos del corazón, cáncer y enfermedades cerebrovasculares, no obstante, un importante número muere de forma violenta o sorpresiva, principalmente por accidentes automovilísticos y de trabajo, víctimas de homicidios, suicidio, y un número significativo de casos permanecen con la causa de muerte desconocida. Es de considerar, al indagar con mayor profundidad sobre las causas de muerte de los migrantes indocumentados mexicanos en general, que pueden estar relacionadas con las dificultades de acceso a servicios de salud, debido al aislamiento y al contexto de clandestinidad en el que desarrollan su vida cotidiana.

El retorno de los fallecidos es predominantemente masculino, de personas que murieron en edad productiva, y que provienen principalmente del estado de California y del de Illinois, en ambos estados, junto con Texas, es donde se encuentran la mayor cantidad de migrantes michoacanos en los Estados Unidos. Regresan a los municipios más poblados del estado, como Morelia, Uruapan, y Lázaro Cárdenas; cuando se toma en consideración el tamaño de su población, los municipios de Chucándiro, Churintzio y Coeneo son los que presentan una mayor tasa de traslados de restos, a la vez que un grado muy 
alto de intensidad migratoria, lo que implica que de manera proporcional, son los municipios a los que han arribado mayor cantidad de cuerpos. En contraste, los municipios de Epitacio Huerta, Chavinda y Ziracuaretiro son los municipios que presentan las tasas de traslados de cuerpos más bajas, a pesar de tener grados muy alto, alto y medio de intensidad migratoria respectivamente. Esto abre la interrogante sobre qué ocurre en esos municipios: ¿acaso hay municipios que pueden gestionar de manera más eficiente los traslados a través de las instancias gubernamentales? ¿O los municipios con alta tasa de traslados reflejan vínculos trasnacionales más consistentes que los municipios con bajas tasas? ¿Los municipios con bajas tasas, experimentan desarraigo o disolución de la vinculación trasnacional entre sus migrantes y las personas que se quedan? Éstas son algunas interrogantes que pueden ser abordadas en futuras investigaciones.

Respecto a las experiencias de los dolientes, los casos abordados refieren a muertes inesperadas, en los que la repatriación de los restos responde más a la aflicción de los familiares, que a las expectativas que los propios migrantes manifestaron en vida. Las principales implicaciones psicológicas para los dolientes de estos casos de fallecimiento, son la ambigüedad, la incertidumbre, la necesidad de construir un relato coherente que explique los hechos ocurridos en espacio y tiempo distintos, y en un contexto social desconocido. De estas implicaciones surge la necesidad de poder ver el cuerpo, de tener la certeza del fallecimiento, que constituye el primer paso del proceso de duelo. La repatriación de los cuerpos contribuye a aliviar de manera parcial el malestar cognitivo y emocional de los familiares, dado que abona una certeza en medio de lo que les resulta incierto: la certeza de la muerte.

El hecho de que los familiares de los occisos, tanto en EUA como en Michoacán, hayan priorizado el deseo de las madres de repatriar los restos, por encima de los probables deseos de las esposas o de los propios migrantes, denota que el vínculo madre - hijo es entendido como único y especial; si bien todos los familiares de los occisos sufrían, reconocían en el sufrimiento de la madre un dolor más intenso y profundo, y en atención a ese dolor fue que decidieron llevar a cabo el traslado de los restos. Esto sugiere que la figura de la madre es un punto de anclaje de las relaciones familiares trasnacionales. En este sentido, el traslado del cuerpo del migrante puede entenderse como un retorno a la madre, a la figura del afecto primario, más que a un retorno a la patria, al terruño, o al lugar de origen.

Las manifestaciones del proceso de duelo, si bien son variadas y remiten a la experiencia particular de los dolientes, permanecieron durante más de dos años en el caso de los participantes. Por ello, es necesario indagar, en éstos y en otros casos de repatriaciones de occisos, si las manifestaciones y síntomas son atribuibles al proceso de duelo de los familiares, lo cual implica que en 
investigaciones futuras se evalúe dicho proceso, y se desarrollen a la par propuestas de política pública para brindar atención a las familias y comunidades que viven experiencias semejantes de pérdida, dolor e incertidumbre. Esta propuesta cobra mayor relevancia en tiempos recientes, puesto que desde el 2019 han disminuido notablemente los apoyos económicos y logísticos que se habían dado para apoyo a la repatriación de cadáveres. Pese a ello, los migrantes en el exterior mantienen actividades colectivas para recolectar fondos que les permitan regresar a los migrantes a su lugar de origen, "al suelo donde han nacido".

\section{- Agradecimientos -}

A los dolientes que dieron testimonio de su experiencia, y a la Secretaría del Migrante del estado de Michoacán por apoyar la realización de esta investigación

\section{Referencias}

ACHOTEGUI, Joseba. Emigrar en situación extrema: el Síndrome del inmigrante con estrés crónico y múltiple (Síndrome de Ulises). Revista Norte de Salud Mental, v. 21, p. 39-52, 2004.

ALONSO, Guillermo. El desierto de los sueños rotos: Detenciones y muertes de migrantes en la frontera México-Estados Unidos 1993 - 2013. Tijuana: El Colegio de la Frontera Norte, 2013.

BOSS, Pauline; YEATS, Janet. Ambiguos loss: a complicated type of grief when loved ones disappear. Bereavement Care. Death Studies, v. 22, n. 2, p. 63-69, 2014.

CALDERÓN, Frida. "Sí se vive la muerte". Ritual en torno a la muerte dentro de la comunidad migrante Patambeña. In: ODGERS ORTIZ, Olga; RUIZ GUADALAJARA, Juan Carlos (coords.). Migración y creencias, pensar las religiones en tiempos de movilidad. Tijuana: El Colegio de la Frontera Norte, 2014, p. 481-521.

CONSEJO NACIONAL DE POBLACIÓN, FUNDACIÓN BBVA BANCOMER Y BBVA RESEARCH. Anuario de Migración y Remesas, México 2018. México: CONAPO-Fundación BBVA Bancomer-BBVA Research, 2018.

FALICOV, Celia Jaes. "Migración, perdida ambigua y rituales". Perspectivas sistémicas. La nueva comunicación, Argentina, n. 69, p. 1-9, 2001. Disponible en: <http://www.robertexto.com/archivo18/migrac_perdida.htm>.

FERNÁNDEZ, Eduardo. Revisión Bibliográfica sobre la migración de retorno. Norteamérica, v. 6, n. 1, p. 35-68, 2011.

MOCTEZUMA, Miguel. Trasnacionalidad y trasnacionalismo. Papeles de la Población, México: Centro de Investigación y Estudios Avanzados de la Población UAEM. Universidad Autónoma de Zacatecas. Nueva Época, v. 14, n. 57, Julio a septiembre de 2008. 
NATIONAL CENTER FOR HEALT STATISTICS (1 de mayo de 2006). National Vital Statistics Reports. Obtenido de Deaths: Final Data for 2005. Disponible en: <http://www.cdc.gov/nchs/data/nvsr/nvsr56/nvsr56_10.pdf>. Acceso en: 30.10.2017.

NATIONAL CENTER FOR HEALTH STATISTICS (17 de Abril de 2009). National Vital Statistics Reports. Obtenido de Deaths: Final Data for 2006. Disponible en: <http://www.cdc.gov/nchs/data/nvsr/nvsr57/nvsr57_14.pdf>. Acceso en: 30.10.2017.

NATIONAL CENTER FOR HEALTH STATISTICS (20 de Mayo de 2010). National Vital Statistics Reports. Obtenido de Deaths: Final Data for 2007. Disponible en: <http://www.cdc.gov/nchs/data/nvsr/nvsr58/nvsr58_19.pdf>. Acceso en: 30.10.2017.

NATIONAL CENTER FOR HEALTH STATISTICS (7 de Diciembre de 2011). National Vital Statistics Reports. Obtenido de Deaths: Final Data for 2008. Disponible en: <http://www.cdc.gov/nchs/data/nvsr/nvsr59/nvsr59_10.pdf>. Acceso en: 30.10.2017.

NATIONAL CENTER FOR HEALTH STATISTICS (29 de Diciembre de 2011). National Vital Statistics Reports. Obtenido de Deaths: Final Data for 2009. Disponible en: http://www.cdc.gov/nchs/data/nvsr/nvsr60/nvsr60_03.pdf. Acceso en: 31.10.2017.

NATIONAL CENTER FOR HEALTH STATISTICS (8 de mayo de 2013). National Vital Statistics Reports. Obtenido de Deaths: Final Data for 2010. Disponible en: <http://www.cdc.gov/nchs/data/nvsr/nvsr61/nvsr61_04.pdf>. Acceso en: 31.10.2017.

NATIONAL CENTER FOR HEALTH STATISTICS (27 de julio de 2015). National Vital Statistics Reports. Obtenido de Deaths: Final Data for 2011. Disponible en: <http://www.cdc.gov/nchs/data/nvsr/nvsr63/nvsr63_03.pdf>. Acceso en: 31.10.2017.

NATIONAL CENTER FOR HEALTH STATISTICS (31 de agosto de 2015). National Vital Statistics Reports. Obtenido de Deaths: Final Data for 2012. Disponible en: <http://www.cdc.gov/nchs/data/nvsr/nvsr63/nvsr63_09.pdf>. Acceso en: 31.10.2017.

NATIONAL CENTER FOR HEALTH STATISTICS (16 de febrero de 2016). National Vital Statistics Reports. Obtenido de Deaths: Final Data for 2013. Disponible en: <http://www.cdc.gov/nchs/data/nvsr/nvsr64/nvsr64_02.pdf.>. Acceso en: 01.11.2017.

NATIONAL CENTER FOR HEALTH STATISTICS (30 de junio de 2016). National Vital Statistics Reports. Obtenido de Deaths: Final Data for 2014. Disponible en: <https://www.cdc.gov/nchs/data/nvsr/nvsr65/nvsr65_04.pdf>. Acceso en: 01.11.2017.

NATIONAL CENTER FOR HEALTH STATISTICS (27 de noviembre de 2017). National Vital Statistics Reports. Obtenido de Deaths: Final Data for 2015. 
Disponible en: <https://www.cdc.gov/nchs/data/nvsr/nvsr66/nvsr66_06.pdf>. Acceso en: 01.11.2017.

ORTíz RUIZ, Juan Carlos. El retorno de los difuntos: repatriación de migrantes michoacanos fallecidos en EUA (Tesis de Licenciatura en Psicología). Morelia, Michoacán, México: UMSNH, 2016.

ORTíz RUÍZ, Juan Carlos; RIVERA HEREDIA, María Elena. Regresar a la tierra de origen, aunque solo sean sus restos. Experiencias de familias que solicitan la repatriación de los migrantes que fallecen en EE.UU. In: CONSEJO NACIONAL DE POBLACIÓN; INICIATIVA DE SALUD DE LAS AMÉRICAS. Migración y Salud. Reflexiones y retos sobre la salud de la población migrante. México, D.F / Berkeley, CA, 2018, p. 131-137.

PEDRAZA RENDÓN, Oscar Hugo; NAVARRO CHÁVEZ, José César Lenin; ARMAS ARÉVALOS, Enrique. Historia de la migración en Michoacán. Cimexus, v. 2, n. 1, 2007, p. 53-66.

SECRETARÍA DE RELACIONES EXTERIORES. Personas mexicanas fallecidas en el extranjero: Repatriación de cadáveres. 2018. Disponible en: <https://datos.gob. $\mathrm{mx} /$ busca/dataset/personas-mexicanas-fallecidas-en-el-extranjero-repatriacionde-cadaveres $>$. Acceso en: 14.01.2019.

TIZÓN, Jorge L. Pérdida, pena, duelo: Vivencias, investigación y asistencia. Barcelona: Paidós, 2004.

WORDEN, William. El tratamiento del duelo: Asesoramiento psicológico y terapia. Barcelona: Paidós, 2013. 